\title{
Developing Capital in Language Learning: A Mixed-Method Study on Vietnamese English Learners
}

\author{
Ngoc Tung $\mathrm{Vu}^{1}$ \\ The University at Albany, SUNY \\ VNU University of Languages and International Studies, Hanoi, Vietnam \\ Thu Hoa Do \\ Hanoi Pedagogical University 2, Hanoi, Vietnam
}

\begin{abstract}
English-as-a-Lingua-Franca's acceleration serves an ultimate goal of preserving English language users' cultural and linguistic identities. In Vietnam, English has emerged as the common language in the education sector, since it aims to equip learners with language proficiency and competence. Hence, it enables the acquisition of linguistic and cultural capital, which is fundamental to accentuate the future Vietnamese workforce's personal commitment and competitive advantage in the globalized labor market. Therefore, this mixed-method study seeks to fill missing literature on how capital is acquired and developed through language learning in Vietnamese higher education, based on the interpretation of Bourdieu's (1986) capital stances in social fields. Among 194 English learners from various cultural and disciplinary backgrounds, data suggested that (1) all forms of capital developed very differently and (2) symbolic capital was directly associated with other forms of capital. Implications are also presented at the conclusion of the article.
\end{abstract}

Keywords: Bourdieusian stances, capital, English language, field, higher education, Vietnam.

Globally, the growing importance of English in various societal fields has continuously required innovations in both teaching and learning. Also, non-native English speakers have outnumbered their native counterparts, making English forms more diverse rather than Standard English because English is now a means of communication for many distinctive purposes (Graddol, 1999; Seidlhofer, 2004). Essentially, this challenges the notion that English is the exclusive property of English-speaking countries (such as the US, the UK, Canada, Australia, and New Zealand). Contrary to popular belief, English language education is common in educational settings where English is not the mother tongue. The educational settings are largely supposed to rely on a means of instruction in which teachers and learners construct and develop linguistic knowledge in relation to which type of English the native-speakers of interest use to communicate. It is revealing the unnecessarily over-considered "special status" of English language speakers in inner-circle countries (Graddol, 1999, p. 67). Therefore, English language education would likely be best if students were assessed by how well they could foster native-like linguistic features (Ho \& Nguyen, 2019). The standardized vocabularies and grammatical structures taught can be at the expense of students' needs related to local English language communication. However, in light of pluricentricity - the English movement in many societal fields and aspects known as World English (Kachru \& Nelson, 1996), English use is

\footnotetext{
${ }^{1}$ Corresponding Author E-Mail: vungoctung2006@ gmail.com
} 
no longer predominantly controlled by English native-speakers and their English-languagerelated attitudes about how to speak and write (Baker, 2016). To demonstrate, many educational perspectives view that English writing and speaking should not overlook established features of language and culture in relation to Anglophone nations (Hu \& Jiang, 2011). Instead, relevant cultural characteristics contribute to English language learners' successes in cross-cultural communication (Kumaravadivelu, 2008). In other words, the English language has not emerged to replace English non-native speakers' linguistic and cultural expressions. Rather, the English language emergence aims to accommodate the continuously changing sociocultural needs in light of globalization and interculturalization.

Canagarajah (2007) claimed that English language users, including learners, should be fully supported to position their cultural and linguistic identities within different forms of the English language. The pluralization of English, expressed under the existence of English varieties, is commonly identified as a Lingua Franca (ELF). Therefore, requiring a move from monolingual (or mono-cultural) language-speaking models to multilingual (or multicultural), because it is used in "interactions between members of two or more different lingua-cultures in English, for none of whom English is the mother tongue" (House, 1999, p. 74). This movement is of growing importance because ELF is fully responsible for assisting speakers in communicating in interconnected contexts around the world, which non-native speakers outweigh native speakers (Jenkins, 2006, 2009; Jenkins \& Leung, 2019; Graddol, 2006). ELF appears to defy the native-speaker models because its users have rights to use it in order to exercise democratic rights and to express their unique identities.

Education in Vietnam continues to gain momentum since the "Open-door" policy in 1986, when the country began to welcome a wider range of overseas investments and foreignowned enterprises, hence offering Vietnamese workers greater chances to work domestically and internationally (Le \& Do, 2012). Importantly, foreign language education has claimed a leading role to equip Vietnamese workers with English language competence (Tran \& Nguyen, 2018), of which they can bolster to acquire "symbolic capital" (Bourdieu, 1989) via influence of other capital. These forms of capital are fundamental to underscore learners' personal commitment and professional advantages to enter the global market. One of the significant English language education reforms, titled Project 2020, was published with the goal to nationally develop Vietnamese graduates to be able to live, study, and work in multilingual and multicultural settings (Government of Vietnam, 2008).

This article examines how Vietnamese learners of English in higher education acquire and develop capital. This mixed-method study employed Bourdieu's stances on capital to explain differential capital development, as well as symbolic capital gains through economic, cultural, and social capital. Bourdieu's (1986) theory on capital is foundational to our questionnaire and semi-structured interviews, which allows us to unpack the voices of English learners in the context of Vietnamese higher education. This study is very important in a sense that it helps to reduce the literature gaps regarding the emergence of capital in language learning, as part of educational research in Vietnam, Asia, and the world. Even though there is well documented research related to capital development as a decisive factor of communicative competence, and career success broadly (Bourdieu, 1986; Bourdieu \& Wacquant, 1992; Islam, 2018; Pham et al., 2018; Pham et al., 2019; Tomlinson, 2017; Xiong \& Yuan, 2018), it remains unexplored whether capital can be developed through language learning among Vietnamese learners. Findings suggest that capital is an effective vehicle to reveal learners' insights from both top-down and bottom-up approaches.

\section{Bourdieu's Theories of Capitals in Language Learning}

According to Bourdieu (1986), capital is defined in terms of either objectified or embodied forms, both of which accumulate over time. In response to those forms, he argued 
that capital exists in both tangible and intangible resources. The development of either resource enables individuals to utilize capital to create profit, or transform it into similar or different forms, including economic capital, cultural capital, social capital, and symbolic capital.

\section{Economic Capital}

Economic capital refers to all forms of wealth, including tangible objects such as money, gold, diamond, cash, material properties, or intellectual resources (Bourdieu, 1986). Economic capital plays an indispensable role in language learning, which assists language learning to take place in various settings, such as formal language courses, social activities, and interactions with cultural artifacts (Bahna, 2017). Understandably, learning environments are seen as contexts where language learners are exposed to experiences that include English use, which ultimately allows them to practice language skills in direct and indirect ways. Theoretically and practically, it should be considered that economic capital is a form of, or result of, academic or professional investment (Burke et al., 2017).

\section{Cultural Capital}

Cultural capital is "acquired, to a varying extent, depending on the period, the society, and the social class, in the absence of any deliberate inculcation, and therefore quite unconsciously" (Bourdieu, 1986, p. 243). Simply put, cultural capital takes on various forms (e.g., values, goods, awareness, behaviors, manners, knowledge, skills, and languages) which can distinguish communities from one another over different points of time. Bourdieu (1986) mentioned three types of cultural capital: embodied, objectified, and institutionalized.

Firstly, embodied refers to cultural resources which are "linked with the body and presupposes embodiment" (Bourdieu, 1986, p. 244). It can be understood as cultural values that are kept either physically or mentally, and can be cultivated or nurtured in a systematic manner. The ways people hold embodied cultural capital vary to different extents, since it is largely decided by peoples' competence to acquire and develop. Secondly, objectified cultural capital refers to cultural artifacts (e.g., paintings, instruments, works, or statues) that present embodied cultural capital. Institutionalized cultural capital is closely linked to engagement in formal and informal education (e.g., certificates, academic qualifications, academic degrees, academic credentials). This is representative of learning where individuals can attend to enhance their language competence. Cultural capital can be considered the backbone of language learners' abilities to perform academically. For example, the influence of cultural immersion differences and learning decisions. Tomlinson (2017) advocated that cultural capital is an instrument to prepare graduates for future employability. Pertaining to Tomlinson (2017), many theorists suggested that English language learners can experience, learn about, and partake in culture through their personal knowledge and cultural backgrounds (Bahna, 2017; Choi \& Jacobs, 2011; Pham et al., 2018; Vu \& Dinh, 2021), thus avoiding "being blinded from the complex and changing reality of English" (Nguyen et al., 2020, p. 2, in Matsuda, 2018).

\section{Social Capital}

Bourdieu (1986) defined social capital as "the aggregate of the actual or potential resources which are linked to possession of a durable network of more or less institutionalized relationships of mutual acquaintance and recognition ..." (p. 246). It supports that learners' engagement and membership in various groups can benefit them. Social capital is contingent on networks, interactions, and recognized values (Li, 2013; Popadiuk \& Authur, 2014; 
Tomlinson, 2017). Societal group memberships enable individuals to grow their sense of cooperation. Memberships can provide opportunities to impact others and collaboratively create values (Andreas, 2018; Bassey, et al., 2019; Islam, 2018; Xia et al., 2020).

\section{Symbolic Capital}

Bourdieu (1989) defined symbolic capital as "a reputation for competence and an image of respectability and honorability" (Bourdieu, 1989, p. 291). Symbolic capital generates fame, prestige, and reputation that can vary. The strength of symbolic capital depends on one's recognition of others' competence, or to what extent their competence is commonly recognized by others. Symbolic capital was first seen as a core component of cultural capital, as the product of embodied cultural capital. However, cultural capital and symbolic capital are now seen as different. While the former perspective viewed culture to develop individually and be recognized by the individual, the latter suggests others contribute to the development and recognition of culture. According to Moore (2013), symbolic capital might involve cultural capital as its sub-group. Therefore, Bourdieu (2013) further suggested that one's objectively measured economic capital and their subjectively measured representation of cultural and social capital contributes to one's ability to participate in a particular cultural group.

\section{Field}

Field is an important emerging term. Fields are structured spaces where singular or combined forms of capital are organized. English language learning in Vietnam is assumed to be concretely established for the purpose of achieving the Government of Vietnam's (2008) educationally inclusive and comprehensive goals. Although, it is valuable to determine how different fields facilitate learning, either advantageously or disadvantageously, when considering Vietnamese learners' diverse backgrounds. Pertaining to Bourdieu's (2013) perspective, Moore (2013) argued that fields are likely to form different types of symbolic capital and control social distribution of that capital.

Language is considered a resource that all learners can accrue and reproduce in various forms of economic, cultural, social, and symbolic capital. As previously suggested, ELF is strongly promoted as a shared language of communication, rather than exclusive to Inner Circle English speakers (Kachru, 1986). Therefore, ELF is available to speakers from backgrounds that permit one to understand and respect others by expressing their linguistic and cultural identities (Holliday, 2007), thus replacing the belief that native-like speaking models must be central to language learning (Jenkins, 2006; Seidlhofer, 2004). In this regard, for effective language learning to take place, learners should engage in environments where they have adequate resources to use and grow capital. Coupled with language competence, learners can obtain resources from other forms of capital. In summary, language users need to be mutually understood and respected, which is an outcome of language competence (Bourdieu \& Passeron, 1990). Although Bourdieu (1999) classified linguistic capital (or language competence) as a typical form of embodied cultural capital, language competence is learned and developed through "a web of significance" in which one explores language from different positions, which is unrelated to the language knowledge and skills needed to communicate. It is imperative that language learners develop language competence, which results in, or from, other forms of capital. Current research in the field of Chinese education (Xiong \& Yuan, 2018), including that of South Korea (Song, 2018) and Pakistan (Islam, 2018), lacks enough evidence that English language teaching and learning supports the acquisition of different forms of capital. Particularly symbolic capital, which is believed to be developed by learners' integration of economic, cultural, and social capital. This mixed-method study not only meaningfully enriches the relevant Vietnamese literature on the topic, but also potentially provides profound 
pedagogical considerations for English language teaching and learning practices for Vietnamese higher education English learners.

\section{Data and Research Methods}

In line with the literature review, the present study will elaborate on our findings in relation to Vietnamese learners of English and their capital development, as well as how economic, social, and cultural capital contributes to symbolic capital. There are four questions:

- To what extent do Vietnamese learners of English acquire and develop capital?

- To what extent does economic capital contribute to symbolic capital?

- To what extent does social capital contribute to symbolic capital?

- To what extent does cultural capital contribute to symbolic capital?

\section{Research Design}

A mixed-method approach was employed to help understand the nature of the phenomenon (Lisle, 2011). We explored the growth of capital, as well as how existing capital assists to develop symbolic capital in Vietnamese learners. There were two primary stages during the investigation, the first one being an online survey to collect quantitative data and the second one being the open-structured interviews. The survey and interview questions were constructed by referring to the current literature, Bourdieusian stances on capital and field, and the relationships between forms of capital.

\section{Participants and Sampling}

Students who were targeted included students that were (1) final-year undergraduate students or fresh-graduates (who graduated in 1-2 years) from either public or private higher education institutions in Vietnam, and (2) learned English during their 4-year courses. A total of 222 students were invited and participated in the research project, 28 responses were incomplete or unreasonable (marking one option for all questions) and thus removed. After removal, 194 responses were used for data analysis, including 86 males and 108 females. It was also observed that (1) there were 101 final-year students and 93 fresh-graduates in the past 1-2 years, (2) there were 98 STEM students (Science, Technology, Engineering, Maths) and 96 Social Sciences and Humanities students (e.g., Economics, Business, Education, Language, and so on), and (3) there were 60 Beginning level learners, 70 Intermediate level, and 64 Advanced level.

Nine out of the 194 participants, each from a different academic discipline, also volunteered to partake in an open-ended interview. The nine students' disciplines included Information Technology, Economics, French Language, English studies, English Interpreting and Translation, Vietnamese studies, Public Relation \& Communication, Chemical Engineering, and Chemist Engineering. The interviews were conducted online via Zoom, with Vietnamese as a means of communication to make them feel comfortable to share their ideas and to avoid any misunderstanding.

\section{Data Collection}

The survey was structured with three primary sections, including (1) demographic information, (2) self-ratings of four capital forms (economic, social, and cultural on a 5-point 
Likert scale with 1 denoting "strongly disagree" and 5 denoting "strongly agree," and (3) the participants' contact information to reach them for interviews. The survey required a minimum of 10 minutes to complete. The responses were checked carefully for missing input, and then responses were removed if found to violate our initial requirement to fully complete all survey fields. We stored our data password protected on a computer and made sure they were only used for research purposes.

The interview questions were centered on participants' lived experiences in their English language learning, helping us to better understand their construction and development of capital through relevant examples. Also, the interviews were aimed to reveal certain economic, cultural, and social capital influences on the emergence of symbolic capital as the ultimate purpose of their personal, academic, and professional growth. The qualitative data were processed using NVIVO software and were cross-checked by the participants to assess the extent to which we accurately interpreted our data based on personal understanding and effort to place ourselves in their positions. As English educators and teachers of more than 5 years, we attempted to utilize our teaching experiences and professional observations to build our critical insights into what the qualitative data revealed.

\section{Settings and Procedure}

The survey was distributed and collected between April and May 2020 on university campuses in Hanoi and Ho Chi Minh City. The participant selection was randomized, and participants were informed of the research's objectives and interview schedule. The analysis was conducted with the Statistical Package for the Social Sciences (SPSS) v.20. Descriptive and inferential statistics calculations were performed to understand the means $(M)$ and standard deviations $(S D)$. Also, principal axis factoring and linear regression were carried out to see the emerging factors and relationships between the factors. .

The semi-structured interviews took place with nine undergraduate students from various disciplinary backgrounds at HE institutions. Nine students were selected based on (1) their participation from the beginning, (2) their willingness to be interviewed for 30-45 minutes, and (3) their disciplinary background. Out of the 09 interviewees, 03 were Beginning level, 04 were Intermediate level, and 02 were Advanced level according to the Common European Framework of References (CEFR) measured after completing the short form of the International English Language Testing System (IELTS). The interviews were conducted in Vietnamese to ease pressure on students' communication skills, which were done over Zoom and were audio-recorded based on students' consent and permission. The interviews were to explore students' experiences learning English and how they utilized capital to prepare for their professional careers. Data were analyzed following a content analysis approach. Interviews were fully transcribed and read through multiple times. We individually coded factors with regards to economic, social, cultural, and symbolic capital. We, the two authors, then discussed the similarities and differences between our codes and decided on the finalized report.

\section{Data Analysis}

This study's official research sample for both quantitative and qualitative data was selected on a random and independent basis. Quantitatively, we initially checked for the normality of distribution of our data using a box plot, which was found to be fairly consistent with a normal distribution. Based on this fact, we ran the correlation between two specific forms of capital as part of the in-depth analysis. When we conducted a pilot study with a smaller group of research students, we ensured that the survey was understandable and clear among the respondents. Many revisions were made to strengthen the quality of the survey based on the comments we received by two experts and the participating respondents. To avoid language- 
related misunderstandings, we translated the survey to Vietnamese after finalizing the best version. The translation was done two ways, as we hired two translators in order to find discrepancies.

The interview protocol was developed by the two authors. We made sure the language to be used would be clear and that there would be very few to no vague expressions. We worked with the data independently before comparing our coding, finding categories, and finalizing themes. Prior to individually reviewing our participants' interview transcripts, our process started by first comparing one participant's transcribed interview and finding strategic differences in our coding approaches. Since we used member checking to achieve data trustworthiness, our qualitatively thematic analyses were regularly checked by our interview participants. The participant checks were important for us to ensure accurate interpretations in our manuscript.

\section{Results}

\section{Quantitative Results: Forms of Capital}

The data were reviewed for internal consistency, the Cronbach's alpha was 0.926, which suggested that the data were reliable for further analysis. Concerning the four forms of capital, the KMO measure of sampling adequacy appeared very high, significantly higher than the minimum KMO value of 0.6 (Tabachnick \& Fidell, 2007). These confirmed that the adequacy of the magnitude of the correlation was met. Details regarding the capital forms are comprised of the following:

- Economic capital: 0.857 (Barlett's test of sphericity: 455.621; $p<0.001$; correlation values ranged between 0.498 and 0.708$)$;

- Social capital: 0.754 (Barlett's test of sphericity: 262.111; $p<0.001$; correlation values ranged between 0.248 and 0.569 );

- Cultural capital: 0.895 (Barlett's test of sphericity: 1009.810; $p<0.001$; correlation values ranged between 0.447 and 0.880 );

- Symbolic capital: 0.736 (Barlett's test of sphericity: 256.385; $p<0.001$; correlation values ranged between 0.355 and 0.663$)$.

The principal axis factoring was performed for each form of capital, in which different established items were clustered based on the Eigenvalue greater than 1.0 with varimax rotation. The scales that resulted from the four separate tests are as follows:

- Figure 1 shows a one-factor scale to Economic Capital (ECO), including 5 items with variance explaining a total of $57.840 \%(\alpha=0.869)$.

- Figure 2 shows a one-factor scale to Social Capital (SOC), including 5 items with variance explaining a total of $41.879 \%(\alpha=0.774)$.

- Figure 3 shows a one-factor solution to Cultural Capital (CUL), including 7 items with variance explaining a total of $62.199 \%(\alpha=0.916)$

- Figure 4 shows a one-factor scale to Capital (SYM), including 4 items with variance explaining a total of $51.370 \%(\alpha=0.790)$. 


\section{Figure 1}

Scree Plot (Economic Capital)

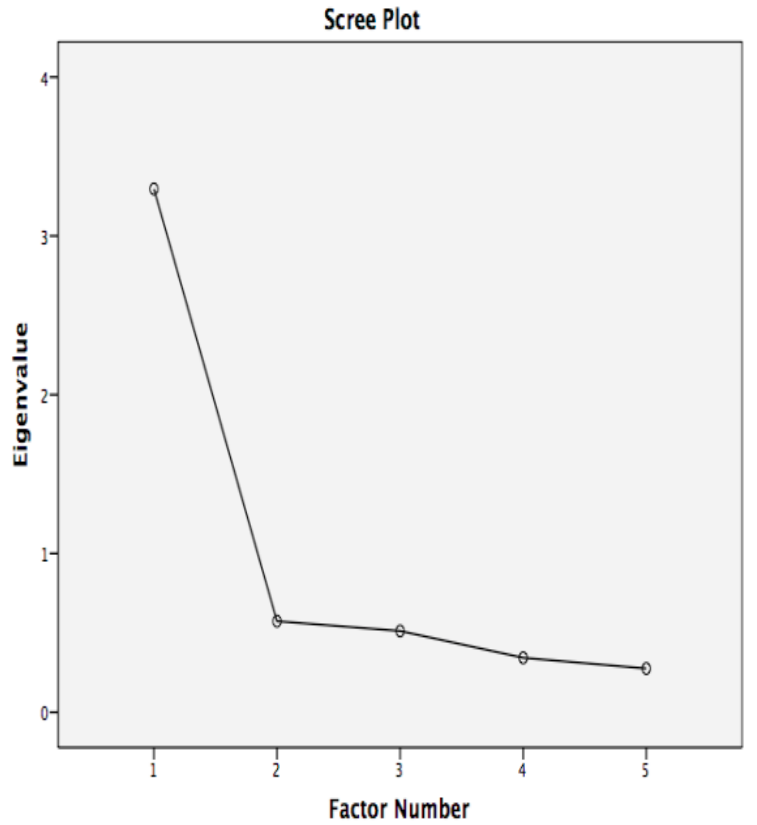

Figure 3

Scree Plot (Cultural Capital)

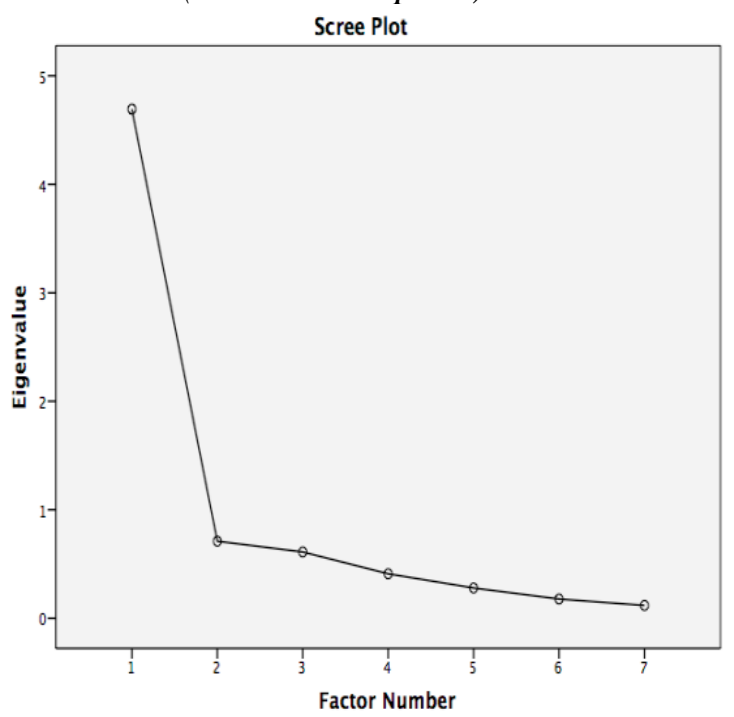

\section{Figure 2}

Scree Plot $\underset{\text { Scree Plot }}{\text { (Social Capital) }}$

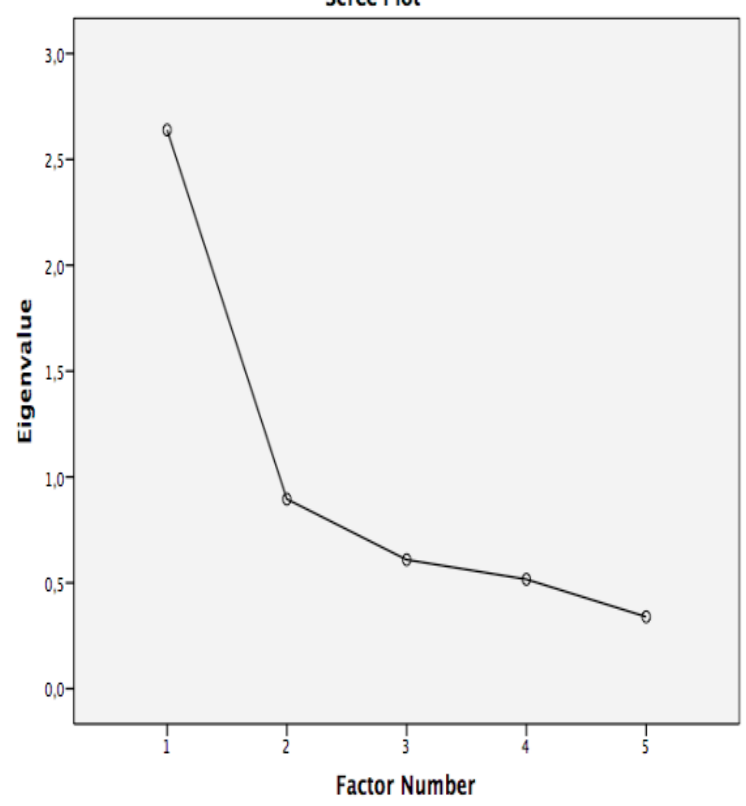

Figure 4

Scree Plot (Symbolic Capital)

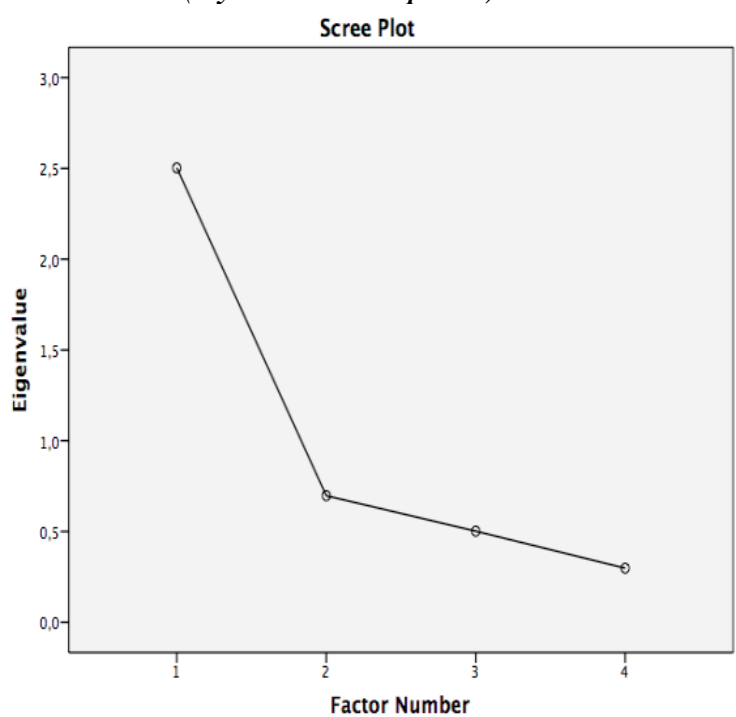

Table 1 shows the variance in terms of Vietnamese English learners' development of the four forms of capital. Following a five-point scale, the calculated means suggested students' levels of acquired capital were moderate. Specifically, they had the highest sense of social capital $(M=3.283, S D=0.760)$. Students' self-rated economic $(M=3.013, S D=0.890)$ and symbolic capital $(M=3.030, S D=0.823)$ were relatively similar in level, higher than that of cultural capital $(M=2.657, S D=0.879)$. 
Table 1

Descriptive Analysis of Capital

\begin{tabular}{|c|c|c|}
\hline & $M$ & $S D$ \\
\hline Economic capital & 3.013 & 0.890 \\
\hline I can afford to attend English classes & 3.330 & 1.070 \\
\hline I can afford to hire personal tutors to teach me English & 2.206 & 1.156 \\
\hline $\begin{array}{l}\text { I can afford to purchase physical or digital learning materials which can support } \\
\text { me to learn English language effectively }\end{array}$ & 3.397 & 1.054 \\
\hline $\begin{array}{l}\text { I can afford to have access to non-formal activities to learn English language } \\
\text { (e.g., paying fees join in any club activities) }\end{array}$ & 3.052 & 1.105 \\
\hline $\begin{array}{l}\text { I can afford to have access to informal activities to learn English language (e.g., } \\
\text { watching paid movies/shows, reading for fun, leisure activities) }\end{array}$ & 3.083 & 1.107 \\
\hline Social capital & 3.283 & 0.760 \\
\hline English language competence is crucial for my social interaction & 4.093 & 0.983 \\
\hline I have people to communicate regularly in English & 2.603 & 1.044 \\
\hline I actively seek to participate in social groups to practice English skills & 2.861 & 1.051 \\
\hline I want to strengthen relationship with people who can speak English & 3.696 & 1.031 \\
\hline $\begin{array}{l}\text { I tend to communicate with those who have similar English language } \\
\text { proficiency }\end{array}$ & 3.160 & 1.129 \\
\hline Cultural capital & 2.657 & 0.879 \\
\hline I have documentation as proof of my English language competence & 2.706 & 1.029 \\
\hline I read many books in English to practice English skills & 2.881 & 1.078 \\
\hline $\begin{array}{l}\text { I am engaged in foreign news on } \mathrm{TV} \text {, radio, newspaper or online sources to } \\
\text { practice English skills }\end{array}$ & 3.057 & 1.107 \\
\hline $\begin{array}{l}\text { I take part in various public events or places to practice with native/non-native } \\
\text { speakers of English }\end{array}$ & 2.624 & 1.091 \\
\hline $\begin{array}{l}\text { I take part in many cultural activities to understand how English is used by } \\
\text { native/non-native speakers of English }\end{array}$ & 2.433 & 1.072 \\
\hline $\begin{array}{l}\text { I take part in many cultural activities to understand cultural differences among } \\
\text { native/non-native speakers of English }\end{array}$ & 2.443 & 1.048 \\
\hline $\begin{array}{l}\text { I utilize English competence as a means of spoken and written communication } \\
\text { to produce artifact products which I own legally or share with others (e.g., } \\
\text { personal blogs, personal sharing, books, or art/scientific performances) }\end{array}$ & 2.454 & 1.120 \\
\hline Symbolic capital & 3.030 & 0.823 \\
\hline My English language competence is well regarded & 2.423 & 0.914 \\
\hline I believe English competence supports my important goals in life & 3.371 & 1.132 \\
\hline People value my efforts in enhancing English language competence & 2.799 & 0.953 \\
\hline $\begin{array}{l}\text { Good English competence helps me feel highly respected in my communities } \\
\text { (class, school, or workplace) }\end{array}$ & 3.526 & 1.179 \\
\hline
\end{tabular}

\section{Quantitative Result: Correlation between Symbolic and Other Capital}

It was hypothesized that changes in economic, social, and cultural capital would individually contribute to symbolic capital to some degree. To address this question, null hypotheses were taken into consideration, concerning the possibility of no effects between economic, social or cultural capital and symbolic capital. The null hypotheses, which were expected to be rejected, were tested at the alpha 0.05 level of significance and with $95 \%$ confidence intervals. 
Preliminary analysis, regarding the existence of simple linear relationships, suggested that the values of deviation from linearity were well above $0.05(p=0.374, p=0.377, p=0.078$ in SYM \& ECO, SYM \& SOC, SYM \& CUL, respectively). Therefore, meaning that they were not statistically significant, and thus allowing us to proceed to explore the quantitative degrees of those linear relationships. Consistent with the histogram and scatterplot of standardized predicted value presented in Figure 6, the assumption of homoscedasticity and linearity $(p>$ 0.050) was met. As presented in Table 2, quantitative findings suggested that the statistically significant positive correlation between 'symbolic capital' and 'cultural capital' was 0.580 ( $p$ $<0.001)$, stronger than the correlation between 'symbolic capital' and 'social capital' ( $r=$ $0.572, p<0.001)$, as well as between 'symbolic capital' and 'economic capital' $(r=0.421, p$ $<0.001$ ), which indicated a range of positive strength from the medium to large.

Table 2

Model Summary

\begin{tabular}{rcccc}
\hline Model & R & R square & Adjusted R square & $\begin{array}{c}\text { Std. Error of the } \\
\text { estimate }\end{array}$ \\
\hline SYM*ECO & $0.421^{\mathrm{a}}$ & 0.177 & 0.173 & 0.749 \\
SYM*SOC & $0.572^{\mathrm{a}}$ & 0.327 & 0.323 & 0.677 \\
SYM*CUL & $0.580^{\mathrm{a}}$ & 0.337 & 0.333 & 0.672 \\
\hline
\end{tabular}

In order to understand whether the correlations were statistically significant, and to find the extent to which each independent variable (economic, social, or cultural capital) was associated with the dependent variable (symbolic capital), we examined the amount of variance in symbolic capital explained by each capital model. In addition to the normally distributed residuals (Shapiro-Will valued higher than 0.05 ), the coefficient tests were run to consider that:

- Economic capital was a statistically significant contributor to symbolic capital $(t=$ $6.424, p<0.001$ ), meaning that $17.7 \%$ of the variance of symbolic capital was explained by by the model containing only economic capital.

- Similarly, social capital was a statistically significant contributor to symbolic capital ( $t$ $=9.655, p<0.001)$, meaning that $32.7 \%$ of the variance of symbolic capital was explained by the model containing only economic capital.

- Consistently, cultural capital was a statistically significant contributor to symbolic capital $(t=9.877, p<0.001)$, meaning that $33.7 \%$ of the variance of symbolic capital was explained by the model containing only cultural capital

Table 3

Coefficients

\begin{tabular}{llccccc}
\hline \multirow{2}{*}{ Model } & \multicolumn{2}{c}{$\begin{array}{c}\text { Unstandardized } \\
\text { coefficients }\end{array}$} & $\begin{array}{c}\text { Standardized } \\
\text { coefficients }\end{array}$ & \multirow{2}{*}{ t } & Sig. \\
\cline { 3 - 5 } & & B & Std. Error & Beta & & \\
\hline SYM*ECO & (Constant) & 1.857 & 0.190 & & 9.764 & 0.000 \\
& ECO & 0.389 & 0.061 & 0.421 & 6.424 & 0.000 \\
\hline SYM*SOC & (Constant) & 0.997 & 0.216 & & 4.616 & 0.000 \\
& SOC & 0.619 & 0.064 & 0.572 & 9.655 & 0.000 \\
\hline SYM*CUL & (Constant) & 1.585 & 0.154 & & 10.287 & 0.000 \\
& CUL & 0.544 & 0.055 & 0.580 & 9.877 & 0.000 \\
\hline
\end{tabular}




\section{Qualitative Findings: Economic Capital}

According to the interview findings, a majority of students claimed they were willing to invest in English language learning based on their personal needs and financial support from their families. Their willingness to invest was considered impactful to their preparation to enter professional careers, which requires a certain level of English proficiency. Personal needs and financial supports varied from learner to learner, but they admitted to the importance of having foreign language competence given that their schools also required them to submit an English certificate. Also, some jobs were in high need of verbal/non-verbal communication in both a mother tongue and the English language.

I was enrolled in English classes which were led by some university lecturers that my friends introduced me to. I found it helpful in two ways, that the course was reasonable based on my mom's financial support and the program was not theoretically heavy in support of practice to communicate in English. Specifically, my pleasure was about my sense of willingness to see the wonderful impacts of the course on my language proficiency (Student of Information Technology (IT)).

With a lot of support from my personal savings, I paid a discounted price to become the premium subscriber of English learning sources designed by English non-native teachers. Feeling very much satisfied with the great price offer based on my tight budget from my faculty's scholarships, I sent my writing back and forth to be commented on and sometimes we chatted to practice speaking with them (Student of Economics).

\section{Qualitative Result: Cultural Capital}

There are three established forms of learning that participants from this research reported on facilitating their learning, which in turn led to their growth of English language knowledge and skills. They were formal, informal, and non-formal learning (Choi \& Jacobs, 2011; OECD, 2005). Firstly, formal learning, but not because they were required to attend academic higher education to satisfy graduation requirements. One student shared that they enjoyed practicing speaking English with their peers through a variety of projects. Their instructors allowed them choose the methods suited to maintain their learning motivation and to build a learning culture in which they and their friends could support each other.
I liked to spend time learning in class with my friends. My instructor gave some experiential learning which immersed us to search for the sources of news about Vietnamese people, Vietnamese lifestyles, and Vietnamese culture in order to let us create a podcast to share on the social media. Although we were unable to speak very fluently, I recognized that we learned something very useful and practical (Student of French language).

Secondly, informal learning (OECD, 2005) was also an alternative, but equally trusted way for participants to develop linguistically and academically. As a passionate language 
learner, one participant engaged in an effective form of learning that led him to work and study at the same time. As cited below, an English-speaking club empowered them to fully participate in language learning. There are a variety of student-led organizations or associations that encourage students to join as members or leaders as a promising foundation to grow their employability skills.

I was interested in joining an English-speaking club in my university where I not only worked as an event organizer but was also unconsciously developing my abilities to speak and write in English very effectively. I had to prepare a lot of materials which enabled the successful organization of weekly speaking sessions. Also, through writing a lot of documents in English, I found my skills have greatly improved, to my surprise (Student of English interpreting and translation).

Thirdly, non-formal learning enabled learners to decide how their learning occurs. For example, through entertaining or relaxing activities. In light of globalization and digitalization, cultural artifacts become varied as they are produced locally and internationally. With an instant click on the Internet, learners can find endless and diverse cultural learning sources.

I relied on YouTube channels to learn about Asian and Western cultures. They are scripted in English and I found they were the excellent source to improve my reading and listening skills. Compared to the textbooks, I think this is far better in terms of giving us a lot of interesting insights on culture which I have never experienced before and it may even let us explore the lives of people in other countries without having pay any cost to visit (Student of Vietnamese studies).

\section{Qualitative Result: Social Capital}

Learning English is regarded as a powerful means of widening learners' networks and reaching communities which interest them. Qualitative findings suggested that language learning facilitated their development of both personal and professional connections. All of the participants discussed benefits to their language learning related to finding resources to increase their job-related chances. The two following excerpts illustrate students' greater sense of belonging and empowerment, hence illuminating evidence of English language learning to develop social capital ( $\mathrm{Li}, 2013$; Popadiuk \& Authur, 2014). One learner discussed the compelling long-term effects that extended her friendship, in addition to professional career:

I used to practice English with a native speaker who lives in Vietnam and her recognition of good English proficiency helped her confidently refer me to a job in her company as an office trainer, consistent with my major. I am still in this job and we are still good colleagues (Student of Public Relations and Communication).

Another participant recalled their experience of engaging in a language contest, seen as a community of practice. The community was diverse in terms of students' cultural backgrounds and academic disciplines, thus enabling not only one student but also other interested students to strengthen their sense of belonging and empowerment. Therefore, it put the students in a position to develop critical thinking by considering the perspectives of others 
with different backgrounds. Due to this experience, they were able to expand their social circles and broaden their academic and personal perspectives.

I joined an English class in a center in my city. The center usually organized some contests to motivate and encourage learners' participation in an attempt to practice speaking and writing abilities. I have seen these contexts as a wonderful space to familiarize myself with strangers and connect with people of similar levels of proficiency and different disciplinary backgrounds to exchange knowledge. We became friends with several ones and we met sometimes (Student of Chemical Engineering).

The two interview excerpts provide insight regarding English-language learners' social capital, it is compelling to see that students with diverse academic disciplines can develop social capital very differently, depending on their cultural identity, personal interests, professional requirements, and linguistic capabilities and goals (Jenkins, 2006). In connection to these two excerpts and other students' unmentioned perspectives, it can help us challenge the fact that English learners, regardless of proficiency level, are able to take many necessary steps (e.g., asking for help, utilizing personal abilities, making trials, and so on) to resolve personal challenges to strengthen their social capital. More importantly, it challenges our stereotypical initial stances that a group of students are unable to develop their fund of social capital particularly and their progress of English language learning in a better than any other counterparts.

\section{Qualitative result: Symbolic capital}

As suggested by Bourdieu (1986), symbolic capital encompasses any other form that is well recognized and credited. The 09 participants positioned themselves very differently based on their strengths and job-related positions pertaining to English language use as non-native speakers, but were privileged to take on challenges to enhance their identity and social standing (Samimy et al., 2011). Furthermore, symbolic capital was well deserved in a sense that learners participated in different forms of learning and practice in a variety of learning contexts. Three exemplary participants displayed their positioning of symbolic capital.

I am a sympathetic learner and listener (Student of French language).

I can read American local news very well and listen to Americans talking to each other very conveniently (Student of English studies).

My friends called me as a good writer and asked me to teach them (Student of Public Relation and Communication).

However, it sparks attention to see that symbolic capital cannot be developed without external factors. Instead, it is exchanged with forms of economic, cultural, and social capital, with symbolic capital being an ingredient to produce the other three mentioned forms of capital or their byproducts. As a critical driver of learners' success, economic capital was found to significantly help participants shape their different identities, including their roles and responsibilities in the numerous communities they belonged to. What can be learned from this 
exchange, is that EFL learners' willingness to grow, and their reflections of growth, were a direct consequence of economic investment.

My informal learning, which is not free of charge, inspired me to distinguish various ways to communicate with people differently so that I do not tend to upset anyone with my personal ways of thought. I don't take my rights for granted because I paid some fees and then endlessly ask for whatever I wanted. It comes to my attention that my benefits always go together with the responsibilities, one of which is to be aligned with the rules of communities that I am engaged in. For example, I should be a good listener and think carefully about how to respond sympathetically. I learned that I should be sensitive to both Vietnamese and foreign people (Student of Chemical Engineering).

Mistakes that I made and were corrected when I studied with an online instructor were effective in terms of how I should write and instruct my students. I think I have done a good job in transferring the economic investments to academic gains. It is clear that I knew well how to build a good essay with clear structure and conveying messages (Student of Chemistry).

Besides the clear impacts of economic capital on symbolic capital, some interviewees shared how their cultural experience in English language learning resulted in them reforming their cognitive, attitudinal, and behavioral engagement in their desired job positions. While they enhanced their foundational knowledge, they acquired attitudes they were expected to form on the job and they became competent to decide how to appropriately behave in workrelated settings. With awareness of this, students were enthusiastic to watch an assortment of internationally-made videos in order to gain knowledge of cultural differences and challenge their cultural stereotypes, which ultimately leads to successful immersion in the globally intercultural working spheres. The following are illustrative examples of how cultural capital and symbolic capital are intertwined. This shows that examples of cultural representations (e.g., bridging people's multiple perspectives, inspiring the book readers, or motivating the future English learners to speak) are compelling enough for cultural builders (including three students below) to recognize others' efforts and contributions (Bourdieu, 1989; Lareau \& Weininger, 2003).

People feel I am very understanding and adapt to people's cultural differences to interact well. As a usual MC for the company's events, I take pride in building the culture where people can be close together and enjoy celebration. I knew various effective strategies to close gaps between people's distinctions and uplift them mentally (Student of French studies).

I am about to write something which can be felt by people although the readers can be different from me culturally and linguistically. I put my feelings into my words and my words can empower people's thoughts. This is absolutely what I learned to write once I read some American comics and autobiography books in English (Student of Vietnamese studies). 
I teach English not just to help students to speak like a native does, but I inspire them to place themselves in others' shoes. This is to enlighten others who can be confident to share stories about lived experiences and hopes (Student of English studies).

The final relationship existed between social and symbolic capital. In other words, social capital served as a condition where Vietnamese learners of English exercised different identities, both of which can be used to gain competitive career advantages. Interestingly, participants' experienced that social relationships acted as a ruler to measure their responses to personal satisfaction and professional achievement, which is aligned with the notion of Wenger (1988).

I am contending with who offered me a sense of learning and was $O K$ to hear me speak ill-grammatically in English. They cared about what ideas I presented and how much effort I enacted to show my understanding. Learning English helped me to become a good listener who was sympathetic to someone that is faced with challenges to speak (Student of French language).

I used English to support my academic career in Australia as a postgraduate student. I worked well with my supervisor and we aimed to write something useful for my school where I work. Toward my future career, I wish to work in a university as an academic advisor and support international students to overcome first-hand experiences. I wish to write something to help them read before coming to study in Aussie (Student of English studies).

Similar to the quantitative findings, the qualitative findings were representative of the formation and correlation of capital in language learning for Vietnamese students in higher education. To recapitulate, (i) economic capital was their financial investment which allowed them to access language learning in different forms, (ii) cultural capital meant students' acquired cultural knowledge and recognized cultural differences, (iii) social capital showed language learners' relational interactions and social developments. Also, the existent relationships between two forms of capital were another contribution to the research on language teaching and learning, including (i) economic and symbolic capital, (ii) cultural and symbolic capital, and (iii) social and symbolic capital.

\section{Discussion}

This study showed that Vietnamese learners of English in higher education have noticed and developed capital in different ways, in line with the characteristics of their learning forms and settings. This is popularly promoted in the context of Vietnamese education, which was triggered by the emergence of social needs to encourage Vietnamese graduates to competently use English in order to ensure effective engagement in the international work-force. Also, a goal was established by the Ministry of Education and Training in Vietnam to improve higher education learning outcomes across the country by shifting attention towards writing effective curriculum in response to work-related skills, most likely giving room to employability (Burke et al., 2017; Chowdhury \& Miah, 2016; Harman \& Nguyen, 2010; Tran \& Nguyen, 2018; Vu $\&$ Dinh, 2021). In response, students have acquired both helpful knowledge and skills required 
for entry into most professions associated with diverse disciplines. Therefore, English language education has played a leading position to accommodate graduates' growing desires to earn professional careers in international and intercultural settings.

According to our quantitative results, students gained capital at a medium strength level in three forms (social, economic, and cultural). These three forms of capital were observed as impactful drivers behind the enhancement of symbolic capital, which was consistent with the observations of Pham et al. (2019) regarding the relationships between capital. Among the types of capital, social capital was ranked in the highest in gains, which is seen in light of Vietnamese culture, where social relationships play important roles in many aspects of life. Driven by societal forces, Vietnamese language learners appeared to become more actively engaged in social platforms where they could obtain resources that interested them personally, academically, and professionally. Such engagement also reinforced their social connections both in depth and width. Findings also supported that language learners attempted to overcome the underlying constraints which may have prevented them from reaching employment success. Therefore, it is seen that being able to communicate in English can be a helpful vehicle to strengthen professional connections internationally, thus creating job opportunities. With regards to financial investments in educational experience, participants stated that they were interested in various methods of learning, both offline and online. However, when compared to hiring a personal tutor, it was suggested that studying in groups was the dominant choice based on their goals and personal preferences. Implicitly, this explains the tendency for Vietnamese learners of English to invest in social relationships with those whom they believe will impact them positively. Consistent with how participants made their learning decisions, cultural capital was revealed quantitatively to some extent. They were more interested in examining authentic materials from English speaking cultures to keep themselves updated in terms of cultural knowledge (Blum-Kulka et al., 1989; Kirkpatrick, 2000; Little et al., 1989). The quantitative results indicated that the preferred choice of learning (e.g., participating in cultural events) was less valued than using physical and digitally-assisted resources. Qualitative findings added that three forms (economic, cultural, and social) allowed them to exercise autonomy and flexibility in an effort to decide knowledge content based on selfassessment of their current proficiency levels and their topics of personal interest.

In response to the acquisition of symbolic capital that Bourdieu referred to as capital value (Grenfell, 2012; Maritz \& Prinsloo, 2015), results highlighted that students' believed English competence has benefited them to achieve their life goals and to be perceived as wellregarded in their communities. Although learners were not confident enough to expand their levels of language proficiency, their aspirations and motivations grew when people they worked with in their social fields recognized their continuous learning efforts. This is truly supported in the globalized context, where Vietnamese workers yield higher chances of employment when they have an acceptable level of proficiency in another language. It is very interesting to note that symbolic capital was statistically correlated with three other capital forms, coupled with the insight that economic, social, and cultural capital are the significant contributors to the construction and escalation of symbolic capital.

Considering the extent to which economic capital contributed to symbolic capital, it is very similar to the emergence and growing importance of education (Bourdieu, 1977; Norris, 2011). Vietnamese people positively refer to education as a worthy long-term investment (Trujillo, 2016). Participants perceived no losses in terms of education's impact on their lifegoals. This is seen as an educational trend, as the transition from high school to higher education represents a cultural norm and higher education degrees are important to the social status of people in Vietnam. Learning from the broader values of education in Vietnamese culture, the globalized and interculturalized job-market has made it possible for Vietnamese learners of English to fruitfully develop their English language proficiency and increase their 
chances of employment. Economically, English language competence takes many forms to learn for growth. We can learn from our findings that, in addition to putting in much effort, making financial investments to grow language competence likely assists integration into the culturally and linguistically diverse communities of practice (CoP). Evidently, high levels of language proficiency as a result of economic capital can increase high-quality employment opportunities. The opposite is true when better employment can provide access to economic gains and learning opportunities. This evidence is considered a two-way exchange between economic and symbolic capital. To promote efficacious and autonomous learning, it is of imperative usefulness that English language learners in the context of higher education should be provided with diverse learning rooms appropriate for their economic capital standing. Then, they can keep pace with their personal responsibilities without undermining their personal goals and motivation to learn. For their ultimate goals, their economic capital should continue to move up from one level to another.

As directly stated above, the driving force of social capital towards symbolic capital cannot be underestimated. That relationship seems to be a decisive factor to facilitate how graduates progress their positioning in the job market (Bassey, et al., 2019; Islam, 2018; Xia et al., 2020). Based on the participants' perspectives, they understood themselves in response to their varying sociocultural contexts. In other words, they identified various social roles that matched the characteristics of mainstream cultures and decided how to overcome the challenges presented in the social fields. We also observed that learners were flexible to reposition themselves to stay humble and accept when they were excluded due to community characteristics (Brown, 1995). This enhanced their competence to be honorable and respectful (Bourdieu, 1989), which contributes to personal contentment and professional achievement. Two examples that were told in the Findings section excellently highlight that social capital cannot be overlooked when language learning occurs. In light of Vietnamese culture, which has long held a collectivist orientation (Nguyen, 2012; Nguyen \& Truong, 2016), it is clearly seen that the promotion of learning culture in which English language learners should strengthen their social connections by participating in different $\mathrm{CoP}$, they also get exposed to English for the sake of their language proficiency. When immersed into authentic learning materials (including $\mathrm{CoP}$ ), learners not only grow their knowledge of culture-laden English language, but also develop employability in many English-speaking communities. Thus, in order to accomplish successful teaching and learning, it is advised that English teachers in the context of Vietnamese classrooms should be adequately provided with professional training. Teachers should innovate instructional methods that allow effective examination of learners' cultural backgrounds, and in turn create more equitable atmospheres where their learners can leverage to work on the shared team-goals based on mutual respect (Bennett et al., 2003). This suggestion should be taken into close consideration because it can transform the traditional ways of teaching and learning that were inspired by an exam-driven culture that undermines students' sense of creativity and cultural understanding.

The reciprocity between cultural and symbolic capital clearly showed that being able to use language effectively requires knowing enough about the culture where the language is used, therefore the impacts of cultural capital are undebatable (Bourdieu, 1977, 1986, 1989; Dovey, 2020; Paige et al., 2003). Statistically, despite being the highest position in terms of capital examined, the impacts of cultural capital were considerably higher than that of economic and social. Practically, irrespective of forms of learning in support of language competence, both qualitative and quantitative results presented an empowering message that language and culture are inseparable, suggesting that the proliferation of English as an international language, or English as a Lingua Franca, has urged learners to consider and regard all users of English in an equal way (Jenkins, 2006; Kirkpatrick, 2012). Specifically, it means 
that how people use and perform language is a representation of their cultural identities and personal prestige. The interviewees mentioned various authentic learning platforms that allowed them to practice various language skills which they found utmost useful, leading them to have greater access to different ways English is employed phonetically, grammatically, pragmatically among culturally diverse people coming from a wide array of geographical locations. Pedagogically, English language teaching and learning practices in Vietnam should be challenged to orient towards the removal of unnecessary native-like speakerism where learners are exposed exclusively to linguistic accuracy, language norms, and cultural representations of English native-speakers (Nguyen, 2013; Ngo, 2013; Ton \& Pham, 2010). In this case, learners should be informed to carry the impactful goals of language learning along their path to reach competence levels which consequently enable them to communicate successfully in different sociocultural settings (Bourdieu, 2011; Choi \& Jacobs, 2011), which fuel their professional career demands.

\section{Conclusion}

Language learning is strongly attached to capital formation and development, which also occurs through tertiary English education in Vietnam. Among Vietnamese learners of English from different cultural and disciplinary backgrounds, they appeared to utilize language learning to different extents in order to develop economic, social, cultural, and symbolic capital (Pham et al., 2018; Pham et al., 2019; Tomlinson, 2017). Acting as an independent variable in the examined relationships between forms of capital, economic capital referred to students' financial strengths that assisted students to access learning resources. Social capital suggested students' attempted to expand their personal network and professional connections with those who supports mutually on various purposes (Islam, 2018; Xia et al., 2020), while cultural capital indicated cultural knowledge and understanding that enabled learners to assimilate and integrate into other diverse settings in which they live or work (Bahna, 2017; Pham et al., 2019).

This study investigated a group of 196 Vietnamese students in terms of their acquisition and development of capital in English language learning. It was important to explore how those forms of capital might interact so that Vietnamese learners can develop many skills in addition to linguistic abilities. Drawing on Bourdieu's (1986) theorization of capital, and other recent theorists in favor of English language learning towards capital development, our data generally showed that participants developed social capital better than other forms, including economic, cultural, and symbolic. It can be explained that Vietnamese learners of English have more room to interact with other speakers of English, such as their local peers or international speakers from a number of digital and authentic platforms (Andreas, 2018; Bassey, et al., 2019). These platforms are vital to exposing them to diverse forms of the English language rather than only Standard English (Nguyen \& Cao, 2019), thus enabling them to have a fuller understanding of how language learning can influence them in many facets of life, in study and work. Secondly, economic capital was enormously attributable to English language learning (Bahna, 2017), which was clear in a sense that the better their language abilities were, the more likely their employability became (Tran \& Nguyen, 2018). Thirdly, it is still questioned that cultural capital was relatively low, but it is understandable when considering that English language learning in Vietnamese classroom contexts is excessively exam-driven and lowers learner motivations. It is suggested that English language learning should orient towards a balance between English for daily use and English for tests in an attempt to increase both intrinsic and extrinsic motivation.

The interactions between forms of capital are illustrative of the fact that language learning is multidimensional, and not only develops learners' language use but also contributes 
to their economic gains, cultural understandings, social circles, and academic/professional achievements. Firstly, economic capital reinforced symbolic capital. This is consistent with the emergence and growing importance of education (Bourdieu, 1977; Norris, 2011). Secondly, social capital contributed to the development of symbolic capital, indicating that social relationships seemed to be a decisive factor in facilitating how graduates would have progressed their positioning in the desired job market (Bassey, et al., 2019; Islam, 2018; Xia et al., 2020). Lastly, the interaction between cultural and symbolic capital suggests that being able to use language effectively goes together with knowing about the culture where the language is used, therefore the impacts of cultural capital are undebatable in importance (Bourdieu, 1977, 1986, 1989; Dovey, 2020; Paige et al., 2003).

Having found an empirical interaction between the capital forms, we turn to pedagogical implications that should be taken into consideration. Pedagogically, the use of cultural characteristics in relation to English language teaching and learning should be at the forefront of materials, content, and assessment practices. Those relevant features are useful to form many meaningful experiences and to motivate Vietnamese learners of English intrinsically (inner dispositions) and extrinsically (social connections). Despite the limited Vietnamese resources that support teaching and learning, it is highlighted that gradual exposure to, and immersion in, authentically cultural-embedded learning materials stimulates learners to better understand the varieties of the English language, and can enable their capital development. If they can develop social capital through confidence to get involved in multicultural and multilingual contexts, they can also foster economic capital thanks to higher chances of employability. Therefore, if capital is gained through English language learning, it is fundamental that English language education in Vietnam becomes more engaging and for the Vietnamese English learners' professional prospects.

This study poses some limitations regarding data collection and analysis. The survey was constructed based on a literature review, and not from initial student interviews. Additional limitations are under investigation concerning the fact that the relationships between economic, social, and cultural capital might have existed, besides acting as the contributors of symbolic capital and vice versa. If these future steps are taken into account, it can potentially improve students' engagement in language learning towards the formation of capital.

\section{References}

Andreas, S. (2018). Effects of the decline in social capital on college graduates' soft skills. Industry and Higher Education, 32(1), 47-56. http://doi.org/10.1177/0950422217749277

Bahna, M. (2017). Study choices and returns of international students: On the role of cultural and economic capital of the family. Population, Space \& Place, 24(2), e2082. http://doi.org/10.1002/psp.2082

Baker, W. (2016). English as an academic lingua franca and intercultural awareness: Student mobility in the transcultural university. Language \& Intercultural Communication, 16, 437-451.

Bassey, E., Ellison, C., \& Walker, R. (2019). Social capital, social relationships and adults with acquired visual impairment: A Nigerian perspective. Disability \& Rehabilitation, 41(10), 1169-1176.

Bennett, J., Bennett, M., \& Allen, W. (2003). Developing intercultural competence in the language classroom. In D. Lange \& M. Paige (Eds.), Culture as the core: Perspectives on culture in second language learning (pp. 237-270). Information Age Publishing. 
Blum-Kulka, S., House, J., \& Kasper, G. (1989). Cross-cultural pragmatics requests and apologies. Ablex Publishing Corporation.

Bourdieu, P. (1977). Outline of a theory of practice. Cambridge University Press.

Bourdieu, P. (1986). Forms of capital. In J. G. Richardson (Ed.), Handbook of theory as research for the sociology of education (pp. 241-258). Greenwood Press.

Bourdieu, P. (1989). Social space and symbolic power. Sociological theory, 7(1), 14-25.

Bourdieu, P. (1999). The order of things. In P. Bourdieu (Ed.), The weight of the world: Social suffering in contemporary society (pp. 60-76). Polity Press.

Bourdieu, P. (2011). On television. Polity Press.

Bourdieu, P. (2013). Symbolic capital and social class. Journal of Classic Sociology, 13(2), 292-302.

Bourdieu, P., \& Passeron, J. -C. (1990). Reproduction in education, society and culture (2nd ed.). Sage.

Bourdieu, P., \& Wacquant, L. (1992). An invitation to reflexive sociology. Polity Press.

Brown, P. (1995). Cultural capital and social exclusion: Some observations on recent trends in education, employment and the labor market. Work, Employment \& Society, 9(1), 2951.

Burke, C., Scurry, T., Blenkinsopp, J., \& Graley, K. (2017). Critical perspectives on graduate employability. In M. Tomlinson \& L. Holmes (Eds.), Graduate employability in context: Theory, research and debate (pp. 87-107). Palgrave Macmillan.

Canagarajah, S. (2007). Lingua franca English, multilingual communities, and language acquisition. The Modern Language Journal, 91, 923-939.

Choi, W., \& Jacobs, R. L. (2011). Influences of formal learning, personal learning orientation, and supportive learning environment on informal learning. Human Resource Development Quarterly, 22, 239-256.

Chowdhury, T. A., \& Miah, M. K. (2019). Developing multidimensional employability skill index: A study of local and multinational companies in Bangladesh. South Asian Journal of Human Resources Management. https://doi.org/10.1177/2322093718821217

Dovey, K. (2020). Becoming places: Urbanism, architecture, identity and power. Routledge.

Government of Vietnam. (2008). Resolution number 1400/QĐ-TTg by the Prime Minister: On the approval of the project 'Teaching and learning foreign languages in the national education system in the period of 2008-2020'. http:// vanban.chinhphu.vn/portal/page/portal/chinhphu/hethongvanban?_page=5\&class_id= $1 \&$ document_id=78437\&mode=detail\&org_group_id=0\&org_id=0\&type_group_id= 0\&type_id $=0$.

Graddol, D. (1999). The decline of the native speaker. AILA Review, 13, 57-68.

Graddol, D. (2006). English next: Why global English may mean the end of 'English as a foreign language'. http://www.britishcouncil.org/learning-research-english-next.pdf

Grenfell, M. (2012). Bourdieu, language and education. In M. Grenfell, D. Bloome, C. Hardy, K. Paul, K. Rowsell, \& B. Street (Eds.), Language, ethnography and education: Bridging new literacies and Bourdieu (pp. 50-70). Routledge.

Harman, K., \& Nguyen, T. N. B. (2010). Reforming teaching and learning in Vietnam's higher education system. In G. Harman (Ed.), Reforming higher education in Vietnam (pp. 6586). Springer.

Ho, T. M. H., \& Nguyen, T. H. (2019). English as a Lingua Franca for Vietnam: Current issues and future directions. In L. V. Cahn, H. T. M. Nguyen, \& T. T. M. Nguyen (Eds.), English-for-everyone policy and its social impact: Discourses, realities, and social impact in Vietnam (pp. 166-183). Routledge. 
Holliday, A. (2007). Response to "ELT" and 'the spirit of the times'. ELT Journal, 61(4), 360365.

House, J. (1999). Misunderstanding in intercultural communication: Interactions in English as a lingua franca and the myth of mutual intelligibility. In C. Gnutzmann (Ed.), Teaching and learning English as a global language (pp. 73-89). Stauffenburg.

$\mathrm{Hu}$, X. Q., \& Jiang, X. X. (2011). Kachru's three concentric circles and English teaching fallacies in EFL and ESL contexts. Changing English, 18(2), 219-228.

Islam, M. (2018). The symbolic capital and expanding roles of English: A study of L2 attitudes in a Pakistani EFL context. Bulletin of Education \& Research, 40(1), 39-56. http://search.proquest.com/docview/205964512

Jenkins, J. (2006). Current perspectives on teaching world Englishes and English as a lingua franca. TESOL Quarterly, 40(1), 157-181.

Jenkins, J. (2009). English as a lingua franca: Interpretations and attitudes. World Englishes, 28(2), 200-207.

Jenkins, J., \& Leung, C. (2019). From mythical 'standard' to standard reality: The need for alternatives to standardized English language tests. Language Teaching, 52(1), 86-110.

Kachru, B. (1986). The alchemy of English: The spread, functions, and models of non-native Englishes. Pergamon.

Kachru, B. B., \& Nelson, C. L. (1996). World Englishes. In S. L. McKay \& N. Hornberger (Eds.), Sociolinguistics and language teaching (pp. 71-102). Cambridge University Press.

Kirkpatrick, A. (2012). English as an international language in Asia: Implications for language education. In A. Kirkpatrick \& R. Sussex (Eds.), English as an international language in Asia: Implications for language education. Springer.

Kirkpatrick, D. (2000). Flexible lifelong learning in professional education. Educational Technology \& Society, 3(1), 24-31.

Kumaravadivelu, B. (2008). Cultural globalization and language education. Yale University Press.

Lareau, A., \& Weininger, E. B. (2003). Cultural capital in educational research: A critical assessment. Theory \& Society, 32, 567-606.

Le, V. C., \& Do, T. M. C. (2012). Teacher preparation for primary school English education: A case of Vietnam. In B. Spolsky \& Y. Moon (Eds.), Primary school English education in Asia: From policy to practice (pp. 106-128). Routledge.

Li, Z. (2013). A critical account of employability construction through the eyes of Chinese postgraduate students in the UK. Journal of Education \& Work, 26(5), 473-493.

Lisle, J. D. (2011). The benefits and challenges of mixing methods and methodologies: Lessons learnt from implementing qualitatively led mixed methods research designs in Trinidad and Tobago. Caribbean Curriculum, 18, 87-120.

Little, D., Devitt, S., \& Singleton, D. (1989). Learning foreign languages from authentic texts: Theory and practice. Authentik in association with CILT.

Martiz, J. \& Prinsloo, P. (2015). A Bourdieusian perspective on becoming and being a postgraduate supervisor: The role of capital. Higher Education Research \& Development. http://www.doi.org/10.1080/07294360.2015.1011085.

Matsuda, A. (2018). Is Teaching English as an International Language all about being politically correct? RELC Journal, 49(1), 24-35.

Moore, R. (2013). Capital. In M. Grenfell (Ed.), Pierre Bourdieu: Key concepts (2nd ed., pp. 101-117). ACUMEN.

Ngo, L. H. P. (2013). An investigation into Vietnamese teachers' and students' perception of English as a Lingua Franca [Unpublished Master's thesis]. University of Southampton. 
Nguyen, D. C. (2013). Cultural diversity in English language teaching: Learners' voices. English Language Teaching, 6(4), 1-7.

Nguyen, M., \& Truong, M. (2016). The effect of culture on enterprise's perception of corporate social responsibility: The case of Vietnam. $13^{\text {th }}$ Global Conference on Sustainability Manufacturing - Decoupling Growth from Resource Use.

Nguyen, T. Q. N. (2012). The Vietnamese values system: A blend of Oriental, western and socialist values. International Education Studies, 9, 3240. https://www.doi.org/10.5539/ies.v9n12p32

Nguyen, T. T. M., \& Cao, T. H. P. (2019). An evaluation of the intercultural orientation of secondary English textbooks in Vietnam: How well are students prepared to communicate in global contexts? In V. C. Le, T. M. H. Nguyen, T. T. M. Nguyen, \& R. Bernard (Eds.), Building teacher capacity in Vietnamese English language teaching: Research, policy and practice (pp. 150-165). Routledge.

Nguyen, T. T. M., Marlina, R., \& Cao, T. H. P. (2020). How well do ELT textbooks prepare students to use English in global contexts? An evaluation of the Vietnamese English textbooks from an English as an international language (EIL) perspectives. Asian Englishes. https://doi.org/10.1080/13488678.2020.1717794.

Norris, E. (2011). Not enough capital? Exploring education and employment progression in further education. RSA Projects.

OECD. (2005). The role of the national qualifications system in promoting lifelong learning: Report from thematic group 2-Standards and quality assurance in qualifications with special reference to the recognition of non-formal and informal learning. OECD.

Paige, R. M., Jorstad, H. L., Siaya, L., Klein, F., \& Colby, J. (2003). Culture learning in language education. In D. L. Lange \& R. M. Paige (Eds.), Culture as the core: Perspectives on culture in second language learning (pp. 173-236). Information Age Publishing.

Pham, T., Saito, E., Bao, D., \& Chowdhury, R. (2018). Enhancing employability of international students: A need to understand and solve their problems on workintegrated learning (WIL) programmes. Journal of Teaching \& Learning for Graduate Employability, 9(1), 62-83.

Pham, T., Tomlinson, M., \& Thompson, C. (2019). Forms of capital and agency as mediations in negotiating employability of international graduate migrants. Globalization, Societies \& Education, 17(3), 394-405. https://doi.org/10.1080/14767724.2019.1583091

Popadiuk, N., \& Arthur, N. (2014). Key relationships for international student university to work transitions. Journal of Career Development, 41 (2), 122-140.

Samimy, K., Kim, S., Ah Lee, J., \& Kasai, M. (2011). A participative inquiry in a TESOL program: Development of three NNES graduate students' legitimate peripheral participation to fuller participation. The Modern Language Journal, 95(4), 558-574. http://dx.doi.org/10.1111/j.1540-4781.2011.01247.x.

Seidlhofer, B. (2004). Research perspectives on teaching English as a lingua franca. Annual Review of Applied Linguistics, 24, 209-239.

Song, J. (2018). English just is not enough!: Neoliberalism, class, and children's study abroad among Korean families. System, 73, 80-88.

Tabachnick, B. G., \& Fidell, L. S. (2007). Using multivariate statistics (5th ed.). Allyn and Bacon.

Tomlinson, M. (2017). Forms of graduate capital and their relationship to graduate. Education \& Training, 59(4), 338-352.

Ton, N. N. H., \& Pham, H. H. (2010). Vietnamese teachers' and students' perceptions of global English. Language Education in Asia, 1(1), 48-61. 
Tran, L. T., \& Nguyen, H. T. (2018). Internationalisation of higher education in Vietnam through English Medium Instruction (EMI): Practices, tensions and implications for local language policies. In I. Liyanage (Ed.), Multilingual education yearbook 2018 (pp. 91-106). Springer International Publishing. http://doi.org/10.1007/978-3-31977655-2_6.

Trujillo, D. (2016). Vietnam places a high value on education. https://www.peoplesworld.org/article/vietnam-places-a-high-value-on-education/

Wenger, E. (1998). Communities of practice: Learning, meaning and identity. Cambridge University Press.

Vu, N. T., \& Dinh, H. (2021). College-level students' development of intercultural communicative competence: A quantitative study in Vietnam. Journal of Intercultural Communication Research. http://doi.org/10.1080/17475759.2021.1893207

Xia, T., Gu, H., Huang, Y., Zhu, Q., \& Cheng, Y. (2020). The relationship between career social support and employability of college students: A moderated mediation model. Frontiers in Psychology, 11, 1-7.

Xiong, T., \& Yuan, Z. (2018). It was because I could speak English that I got the job. Neoliberal discourse in a Chinese English textbook series. Journal of Language Identity \& Education, 17(2), 103-177. https://www.doi.org/10.1080/15348458.2017.1407655

\section{Notes on Contributors}

Ngoc Tung $V \boldsymbol{u}$ is a doctoral student at The University at Albany, SUNY. He is also a Lecturer of English at University of Languages and International Studies, as a member of Vietnam National University, Hanoi City. His research interests cover intercultural communication, teacher education programs. He has published many articles in the top-tier journals in the related fields. He can be reached at vungoctung2006@gmail.com; ORCiD: 0000-0002-7661-2885

Thu Hoa Do is currently a Lecturer of English at Faculty of Foreign Languages at Hanoi Pedagogical University No.2. She holds a Master's Degree in TESOL from Victoria University. She has more than 7 years of teaching experience. Her research interests lie in teaching pedagogy, teacher autonomy, testing and assessment. She can be reached at dothuhoa223@gmail.com; ORCiD: 0000-0003-0778-3119 